\title{
Mystery behind Malocclusion: Report of Two Mesiodens Cases
}

\author{
Sandhyarani $\mathbf{B}^{1}$, Dayanand Huddar ${ }^{2}$ \\ ${ }^{1}$ (Department of Pedodontics, Bharati Vidyapeeth Dental College and Hospital/ Bharati Vidyapeeth deemed \\ University, Sangli, India). \\ ${ }^{2}$ (Department of Prosthodontics, Bharati Vidyapeeth Dental College and Hospital/ Bharati Vidyapeeth deemed \\ University, Sangli, India).
}

\begin{abstract}
Mesiodens is the most frequent disorder of odontogenesis which is located between the two maxillary central incisors. In most of the cases mesiodentes are asymptomatic and are diagnosed on routine clinical or radiographic examinations. Various complications associated with mesiodens are crowding, displacement, delayed eruption of adjacent teeth, diastema, root resorption and sometimes dentigerous cyst formation. The purpose of this article is to present two cases of mesiodentes causing malocclusion and its correction by surgical intervention.
\end{abstract}

Keywords: Hyperdontia, Malocclusion, Mesiodens, Polydontia, Surgical intervention.

\section{Introduction:}

Supernumerary teeth or hyperdontia, is defined as an excess number of teeth when compared to the normal human dental formula ${ }^{1}$ which was first reported between AD 23 and 79. ${ }^{2}$ Prevalence of supernumerary teeth in various populations is ranging between $0.1-3.8 \%$ with a male to female ratio of 2:1. ${ }^{3}$ Supernumerary teeth may occur in single, multiple, unilaterally or bilaterally and in one or both jaws ${ }^{4}$ and are classified as either supplemental or rudimentary. ${ }^{5}$

Mesiodens, which means middle tooth, is the most frequent supernumerary tooth ${ }^{6}$ and is used to refer to an unerupted supernumerary tooth in the midline of maxilla, between the two central incisors ${ }^{7,8}$ and may vary in shape from simple conical form to a larger , more complicated crown shape with a number of tubercles. ${ }^{7}$ They occur more commonly in the permanent dentition (prevalence of $0.10-3.6 \%$ ) when compared to the primary dentition (prevalence of $0.02-1.9 \%)^{9}$ with overall prevalence between $0.15 \%$ to $1.9 \%$. $^{10,11}$

According to various theories the etiology of mesiodens is still unclear. Among them one theory suggests that the supernumerary tooth is created as a result of a dichotomy of the tooth bud. ${ }^{12}$ Another theory, well supported in the literature, is the hyperactivity theory, which suggests that supernumeraries are formed as a result of local, independent, conditioned hyperactivity of the dental lamina. ${ }^{12,13}$ Frequently mesiodentes are associated with various craniofacial anomalies, including cleft lip and palate, Gardner's syndrome and cleidocranial dysostosis. ${ }^{14}$

This paper reports two cases of mesiodens, one impeding the eruption of permanent maxillary incisors and other causing midline diastema and proclination of maxillary central incisors, emphasizing on proper radiographic diagnosis and its management.

\section{Case Reports:}

Case 1: A 14yr old boy reported with the chief complaint of forwardly placed upper front teeth and wanted its correction. No much contribution was there from his family, dental and medical histories. On intraoral examination, patient had proclined maxillary central incisors and a clearly visible clinically erupted mesiodens(Fig:1). On taking intra oral periapical radiograph, another impacted inverted mesiodens was present just above the clinically erupted mesiodens(Fig:1). SLOB technique revealed that the impacted mesiodens was present more labially than palatally. The treatment plan consisted of extraction of the one which is clinically erupted and surgical removal of the impacted ones under local anesthesia. After the extraction of erupted mesiodens, mucosal flaps were opened and a window was created to access the impacted inverted mesiodens(Fig:2). Elevators were used to remove it out and sutures were placed. Following the suture the patient was scheduled for 1 week recall for the removal of sutures. Radiograph was taken to assure the removal of both the mesiodens (Fig:3). Now the patient is taking orthodontic treatment for the proclined maxillary anteriors and is under regular follow-up.

Case 2: A $11 \mathrm{yr}$ old boy reported with the chief complaint of unerupted tooth in upper front region of mouth. His family, dental and medical histories were noncontributory. On intra-oral examination a clearly visible soft tissue impacted maxillary right central incisor and a bony impacted mesiodens was present (Fig:4). On radiographic examination one impacted mesiodens was visible (Fig:4). SLOB technique revealed that the impacted mesiodens was present palatally. Orthodontic extrusion was done with central incisor (Fig:5.1), but the 
erupting tooth appeared to be rotated because of presence of impacted mesiodens(Fig:5.2), hence surgical removal of impacted mesiodens was done after few months of orthodontic extrusion(Fig:5.3). After 6months of followup almost complete eruption of permanent central incisor occurred(Fig:6) and patient is still under observation.

\section{Figures and Tables:}

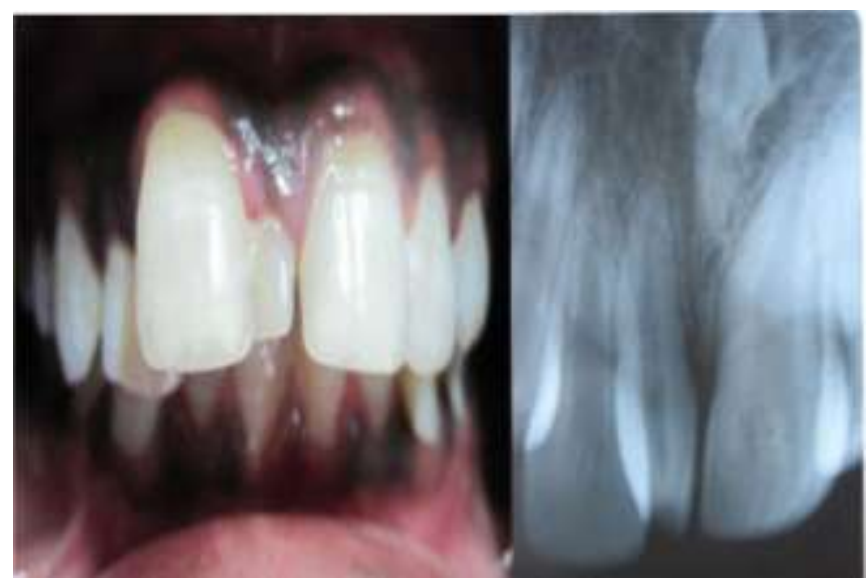

Fig: 1: Pre-operative intraoral photograph and radiograph of case I.

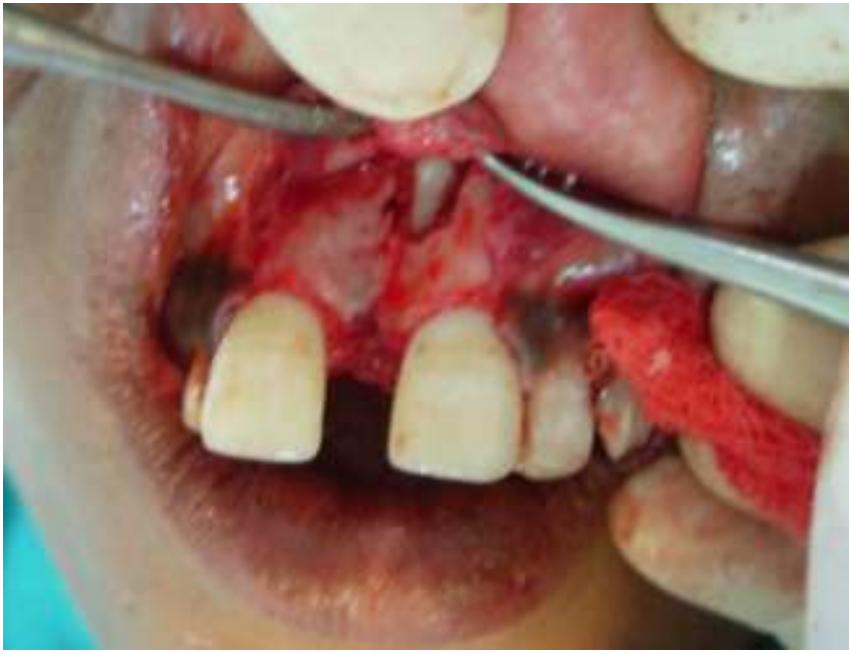

Fig: 2: Exposure of impacted mesiodens of case I.

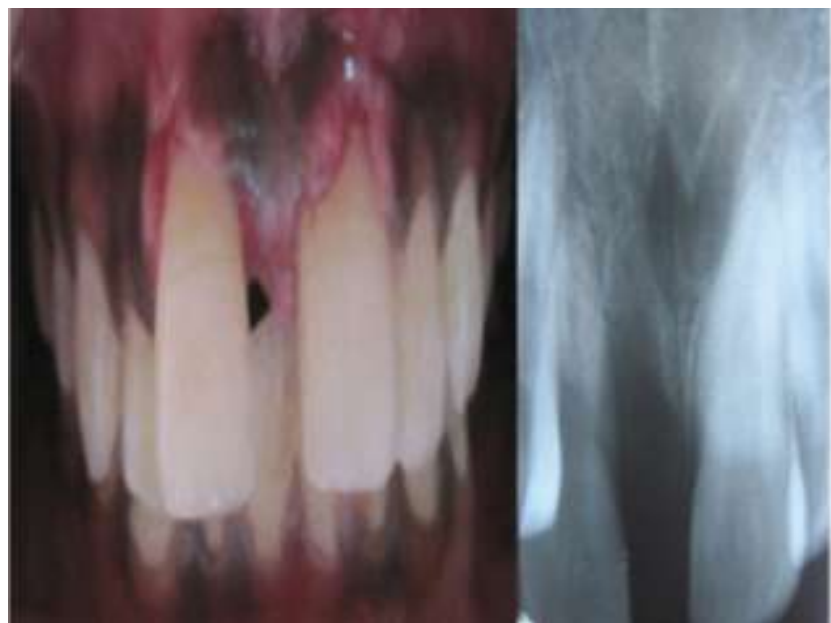

Fig: 3: Post-operative photograph and radiograph of case I. 


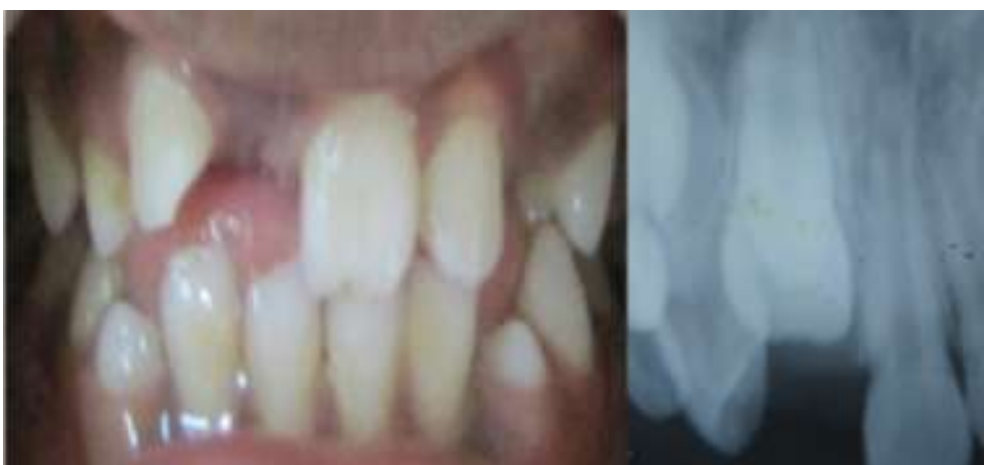

Fig: 4: Pre-operative photograph and radiograph of case II.

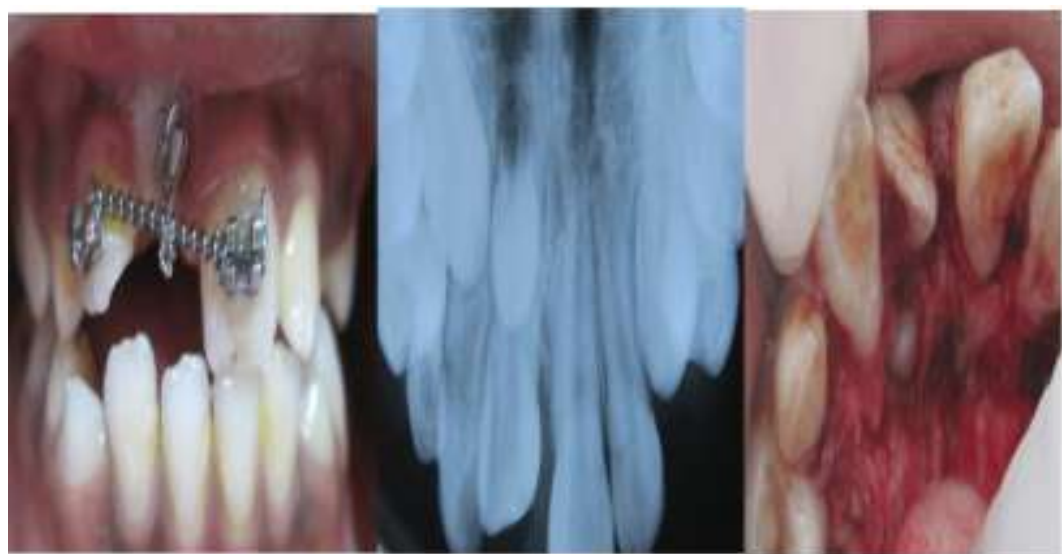

Fig:5.1: Orthodontic extrusion of impacted tooth Fig:5.2: Occlusal radiograph showing impacted mesiodens Fig:5.3: Exposure of impacted mesiodens of case II.

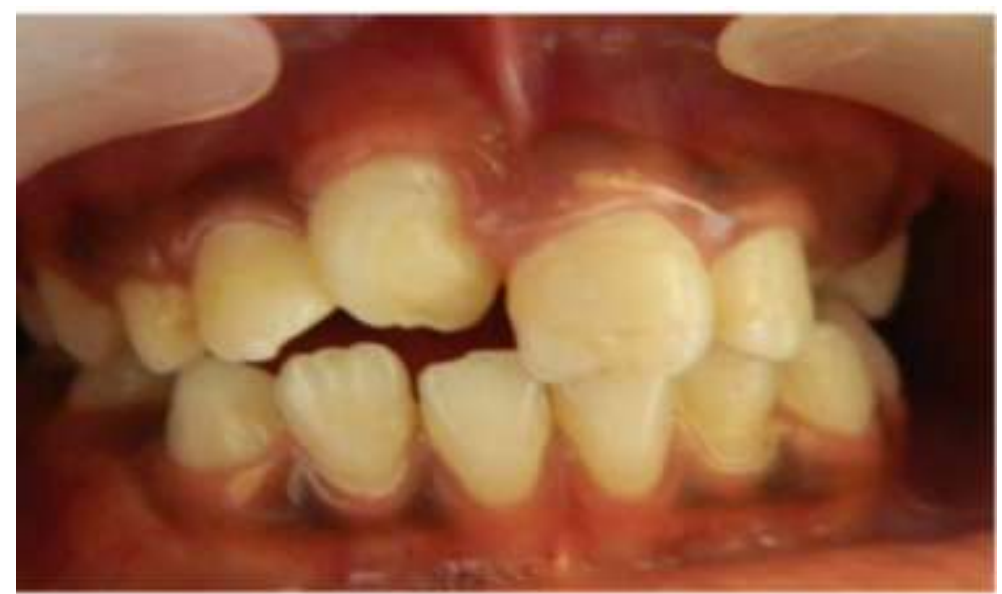

Fig:6: post-operative photograph after 6monthsof case II.

\section{Discussion:}

Any increase in number of teeth from normal primary and permanent complement is known as hyperdontia. The presence of extra or supernumerary tooth is also known as polydontia or polygenesis but widely accepted one is hyperdontia. ${ }^{17}$ The vast majority of supernumerary teeth are associated with the permanent dentition and occur predominantly in the premaxillary midline region and are termed mesiodens. ${ }^{5}$ Mesiodens are usually found to be impacted, with conical shape, single root and also most of the times inverted. ${ }^{15}$ In a study done by Nagaveni et a ${ }^{16}$, out of 27 mesiodentes, $23 \%$ caused midline diastema, $14.8 \%$ occlusal interference, $7.4 \%$ root resorption, and $3.7 \%$ had caused delayed eruption of permanent incisors.

Treatment of mesiodens centers on several factors and consideration of these variables will determine whether to treat the supernumerary early or to observe the condition. The first factor is the child's age. In the very young child the ability to tolerate a surgical procedure is of major concern. The benefit of early treatment must be weighed against the long-term effect that any unpleasant experience may have psychological effect on 
child. ${ }^{5}$ Second is the stage of dental development of the surrounding dentition and proximity of the mesiodens to the permanent incisors. In cases of immature root development, consideration must be given to the risk of surgical trauma to the developing roots of the permanent incisors and the potential of altering future dental development. Mesiodens that are intimately positioned with the developing permanent incisors may alter the permanent bud positionally, impede eruption, and/ or alter root development; whereas, removal of this same supernumerary tooth may cause the same sequelae through surgical trauma. In instances where the surgical approach jeopardizes the viability of sensitive developing tissue, it may be appropriate to delay treatment. Lastly, one must evaluate the relative position of the mesiodens within the premaxilla. Assessment of access to the supernumerary must be considered in relation to the amount of bone removal and potential damage to existing incisors. In children, eruption of mesiodens is possible and, although complete eruption is infrequent, some mesiodens may erupt partially so that a more favorable surgical approach may be attained with time. ${ }^{5}$

\section{Conclusion:}

In both the cases reported, surgical intervention was decided as the children were mature enough to take up the surgery and also we found that mesiodens affected the permanent maxillary central incisors positions. In the present cases, the timing for surgical removal of inverted mesiodens was judged suitable, showing complete root formation and advanced apical closure.

\section{References}

[1] Primosch R.E. Anterior supernumerary teeth - assessment and surgical intervention in children. Pediatric dentistry 1981;3(2)204215.

[2] Maya C, Ashok Kumar BR. Familial occurrence of mesiodens with unusual findings: Case report. Quintessence Int 1998;29:4951 .

[3] Sharma A. Familial occurrence of mesiodens: A case report. J Indian Soc Pedo Prev Dent 2003;21:2.

[4] Rajab L.D, Hamdan A.M. Supernumerary teeth: review of the literature and a survey of 152 cases. International journal of pediatric dentistry 2002; 12: 244- 254

5] Henry RJ. A labially positioned mesiodens: a case report. Pediatric Dentistry1 989; 11(1):59-63.

[6] Galas MM, Garcia A. Retention of permanent incisors by mesiodens: a family affair. Br Dent J 2000;188:63-64.

[7] Seddon RP, Johnstone SC, Smith PB. Mesiodentes in twins: a case report and a review of the literature. Int J Paediatr Dent.1997;7:177-184.

[8] Segura JJ,Jimenez-Rubio A. Concomitant hypohyperdontia: simultaneous occurrence of a mesiodens and agenesis of a maxillary lateral incisor. Oral Surg Oral Med Oral Pathol Oral Radiol Endod.1998;86:473-475.

[9] Arathi R, Ashwini R. Supernumerary teeth: A case report. J Indian Soc Pedo Prev Dent 2005;23:103-5.

[10] Sedano HO, Gorlin RJ. Familial occurrence of mesiodens. Oral Surg Oral Med Oral Pathol 1969; 27(3):360-1.

[11] Sykaras SN. Mesiodens in primary and permanent dentitions. Report of a case. Oral Surg Oral Med Oral Pathol 1975; 39(6):8704.

[12] Liu JF. Characteristics of premaxillary supernumerary teeth: A survey of 112 cases. ASDC J Dent Child 1995; 62:262-5.

[13] Levine N. The clinical management of supernumerary teeth. J Can Dent Assoc 1961; 28:297-303.

[14] Russell K A, Folwarczna M A. Mesiodens — Diagnosis and Management of a Common Supernumerary Tooth. J Can Dent Assoc 2003; 69(6):362-6.

[15] Gunduz K, Celenk P, Zengin Z, Sumer P. Mesiodens : a radiographic study in children. J of Oral Science 2008;50(3):287-291.

[16] Nagaveni NB, Sreedevi B, Praveen BS, Praveen Reddy B, Vidyulatha BG, Umashankara KV. Survey of mesiodens and its characteristics in 2500 children of Davangere city, India. Eur J of Ped Dent 2010;11(4):185-188.

[17] Lukas JR. Mesiodens in India: a brief review of hyperdontia with new frequency data for castes and tribes of South Asia. Dental Anthropology newsletter. A Publication the dental anthropology association 1995;10(1):2-5. 